\title{
Recovery of substrates and macro-benthos after fishing trials with a new Portuguese clam dredge
}

\author{
M.B. Gaspar* ${ }^{\ddagger}$, M.N. Santos*, F. Leitão*, L. Chícharo ${ }^{\dagger}$, A. Chícharo ${ }^{\dagger}$ and G.C. Monteiro* \\ *Instituto de Investigação das Pescas e do Mar (IPIMAR), Gentro Regional de Investigação Pesqueira do Sul (CRIPSul), \\ Avenida 5 de Outubro s/n, P-8700-305 Olhão, Portugal; ${ }^{\dagger}$ Universidade do Algarve (UAlg), Faculdade de Ciências do Mar e do \\ Ambiente (FCMA), Campus de Gambelas, P-8000-117 Faro, Portugal; ${ }^{\ddagger}$ Corresponding author, e-mail: mbgaspar@ipimar.ualg.pt
}

The effect of dredging on bottom structure was assessed, to estimate the damage inflicted on the benthic macrofauna left on the dredge path and to evaluate aggregations of scavengers within the track. Sediment suspended during dredging rapidly resettled both on sand and sandy-mud bottoms. Dredge tracks were deeper on sandy-mud sediments and persisted longer than in sandy sediments. The disappearance of tracks in both sediment types depended both on current strength and wave action. Damage and mortality induced by dredging on the macrobenthic animals left on the dredge path was relatively low. Post-fishing diver observations showed that damaged animals left on the dredge path rapidly attracted scavengers, mainly Ophiura albida. Immediately after the tow ophiuras reached densities 8 times greater in the track region than in the background. However, they dispersed again rapidly because only few damaged fauna were available on the dredge tracks. Undamaged or slightly damaged shellfish started to rebury immediately after escaping from the dredge.

\section{INTRODUCTION}

Clam dredges disturb the sediment and may have an impact on the structure and composition of the seabed. For example, changes in grain-size of the sediment may occur as a result of the transport of fine sediments during sediment suspension.

Dredges also induce mortality in non-target benthic species and undersized individuals of the target species that are discarded or left in the dredge path. Animals dislodged or damaged by the passage of a dredge and left on the dredge path are known to attract mobile epifauna (eg. Medcof \& Bourne, 1964; Caddy, 1973; Kaiser \& Spencer, 1994). Scavenger activity within a dredge path is determined by the number of damaged fauna left on the track.

Recently, a new dredge was introduced in the Portuguese bivalve fishery, which is more efficient and selective than the traditional dredge used by the commercial fleet (Gaspar et al., 2001; Gaspar et al., in press). However, the general effect of this new dredge, both on the substratum and macrobenthic fauna left within the dredge path, was unknown. The present study reports the results of a diving investigation to assess the effects of dredging on bottom substrata, to estimate the damage inflicted by this new dredge on benthic macrofauna left on the dredge path, and to evaluate aggregation of scavengers within the track.

\section{MATERIALS AND METHODS}

The study was undertaken in July 2000 off Lagos (south Portugal) on-board the RV Donax. The dredge was identical to those used by the commercial dredge fleet (Gaspar et al., in press). During ebb tide tows were made parallel to the coastline in an east-west direction. Due to dive time constraints the studies concerning 'Mortality of the macrofauna left on the track' and 'Aggregation' were only undertaken on hauls performed on sandy bottoms at $5 \mathrm{~m}$ depth.

\section{Track configuration and breakdown}

To evaluate the influence of depth and sediment type on structure and persistence of dredge tracks, tows were made at depths of 5 and $12 \mathrm{~m}$, in sand and sandy-mud bottoms. For each depth/sediment combination 3 hauls (for $1 \mathrm{~min}$ at a towing speed of 1-1.5 knots) were made with a commercial dredge. The beginning and the end of the dredge path were marked by buoys and the distance between the buoys measured. After each haul divers swam along the dredge path to characterize the dredge tracks, measuring depth and width in the middle of the track. To evaluate the persistence of dredge tracks the path depth was measured immediately after the tow and again 1, 2, 4, 6,12 and 24 hours later. These experiments were undertaken on four consecutive days.

\section{Mortality of the macrofauna left on the track}

To estimate the number of damaged macrofaunal individuals left on dredge tracks, divers collected sediment samples. At each dredge path, 18 quadrats (quadrat area $=0.0625 \mathrm{~m}^{2} \times 0.15 \mathrm{~m}$ depth) were collected: 6 in the beginning, 6 in the middle and 6 at the end of the track. Samples were sieved in situ through a 5-mm mesh bag. On board, all animals collected were preserved in $70 \%$ ethanol, to be identified and counted in the laboratory. A three-level damage score was attributed to each specimen caught: score 1 corresponding to individuals in perfect condition and score 3 for animals heavily damaged. 


\section{Aggregation}

Background densities of epibenthic scavenging species were estimated by means of six diver surveys over $100-\mathrm{m}^{2}$ transects. For each survey divers followed a $50 \mathrm{~m}$ long bottom line marked every $5 \mathrm{~m}$ counting the number of organisms within each mark on both sides of the line, which results in a width of each transect of $2 \mathrm{~m}$. To assess the aggregation of predators and/or scavenging species attracted by damaged animals within the dredge tracks, divers made video recordings of the tracks, using a digital video camera, immediately after the haul and again after $10,20,30$ and $60 \mathrm{~min}$.

\section{Data analysis}

To estimate the aggregation of predators and/or scavengers in the dredge track, the video tape recordings were viewed and instantaneous counts of all individuals within the track were made every 1-min of real time. To test the accuracy of data gathered from underwater video images, independent reviews of the videotapes were made.

Analyses of variance ANOVA or Kruskal-WallisANOVA were used to test differences both on the number of scavengers within the dredge path through the duration of the experiments, and on the proportion of damaged individuals (scores 2 and 3 ) in the beginning, middle and end of the dredge path. Multiple comparisons were performed using the Student-Newman-Keuls test. Prior to the application of the above tests, in order to approximate normality, data were converted to square root, and to arcsine square root values when expressed as a percentage. SigmaStat ${ }^{\circledR}$ software was used for all statistical analysis.

\section{RESULTS}

\section{Track configuration and breakdown}

During tows on sandy bottoms the sediment cloud behind the dredge seldom exceeded $1 \mathrm{~m}$ height and settled quickly and evenly within 1 minute. On sandy-mud sediments, the cloud created during tows was $2-3 \mathrm{~m}$ high and settling took about 3-5 minutes. The dredge paths were 45 metres long and $60 \mathrm{~cm}$ wide and very similar in both sediments, with smooth and steeply cut edges and a flat floor. The track average depths were slightly deeper $(17 \mathrm{~cm})$ in sandy-mud bottoms than in sand bottoms $(15 \mathrm{~cm})$. The track shoulders formed during the tow, varied along the dredge track. In the beginning of the dredge path the track shoulders were $5 \mathrm{~cm}$ wide and $5 \mathrm{~cm}$ high, whilst on the middle and end of the track the shoulders were $15-20 \mathrm{~cm}$ wide and $3-5 \mathrm{~cm}$ high.

Figure 1A,B shows the change in depth of dredge tracks, in sand and sandy-mud bottoms within a period of 24 hours, at 5 and $12 \mathrm{~m}$ depth, respectively. On sand bottoms at both depths the track walls slumped immediately after the tow. In the 2-hour old track slumping of the walls had created a more rounded depression, the track shoulders had decreased in height and the depth of the dredge path had also decreased. After 6 hours the mean depth of the dredge path had decreased to $11 \mathrm{~cm}$ and to $7 \mathrm{~cm}$ after 12 hours, and the dredge shoulders had almost disappeared. At the end of the observations (24-hour old track) the dredge path was difficult to recognise, since the dredge
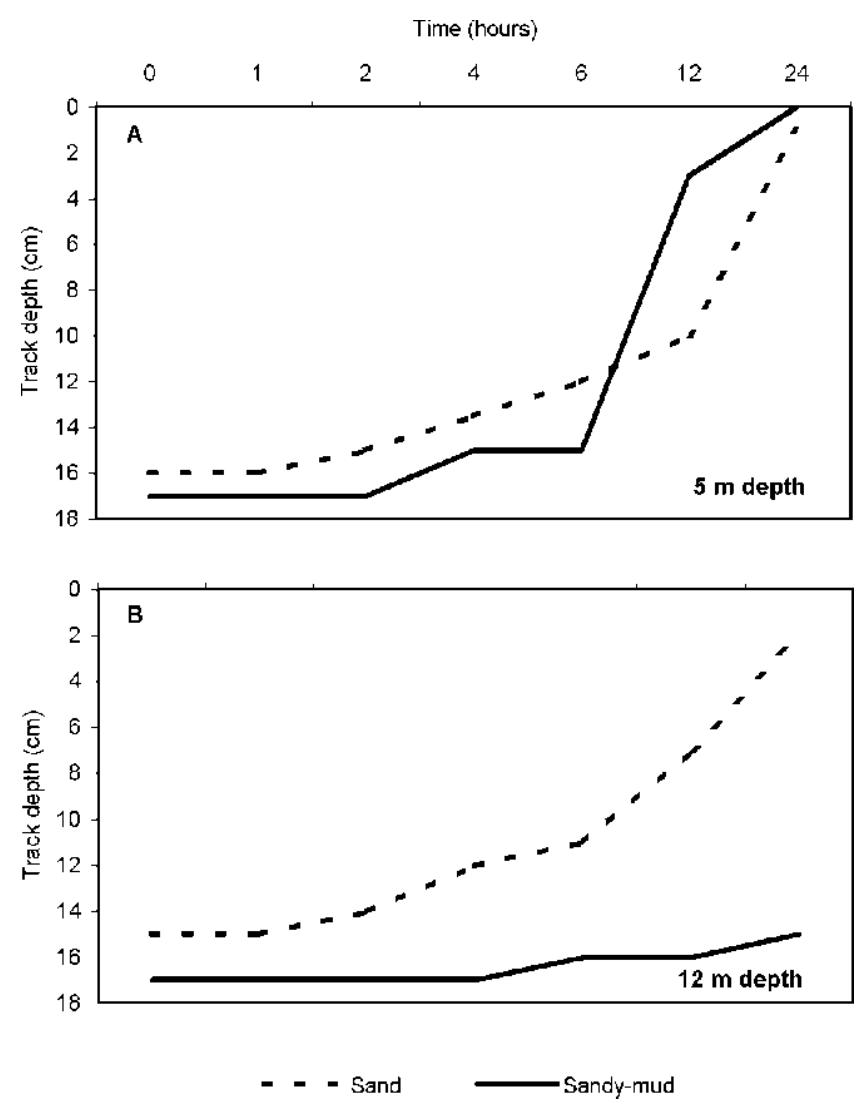

Figure 1. Evolution of dredge track on sand and sandy-mud bottoms at 5 metres depth (A) and at 12 metres depth (B).

shoulders had completely disappeared and the track was blended in with general bottom features (sand ripples).

On sandy-mud bottoms at $12 \mathrm{~m}$ depth the dredge path remained almost unchanged for 24 hours and the track average depth decreased only $2 \mathrm{~cm}$. The dredge path seemed to be filled in by sediment transport rather than by slumping of sediment from the walls and the dredge shoulders also remained perfectly visible. At $5 \mathrm{~m}$ depth, the dredge path left on sandy-mud bottoms remained almost unchanged for 6 hours after the tow. However, within 12 hours the path shoulders were eroded and the mean depth of the path decreased to $3 \mathrm{~cm}$, while after 24 hours the dredge tracks had become indistinguishable from the surroundings. The reason for the rapid disappearance of the dredge tracks was mainly due to the sea condition, since at the end of that day there were intense southeastern winds that caused the formation of waves (2-3 $\mathrm{m}$ high). The wave action induced disturbance in bottom sediment, leading to a rapid disappearance of the track left by the dredge.

\section{Mortality of the macrofauna left on the track}

After dredging on sandy bottom at $5 \mathrm{~m}$ depth divers collected a total of 10 species from the dredge path. The most abundant group was Bivalvia, comprising approximately $95 \%$ of the animals found on the tracks, particularly Chamelea gallina, Donax trunculus, Spisula solida and Tellina tenuis. The estimated proportions of individuals on the dredge track, which suffered damage, were very similar for the three tows performed, varying between $13 \%$ and $14 \%$, 
Table 1. Number of individuals per damage score and species collected from the dredge track and length range of the organisms left in the dredge path and retained by the gear. Figures are means for 3 tows of approximately $45 \mathrm{~m}$ length at $5 \mathrm{~m}$ depth on sandy substrate. $L=$ shell length $(\mathrm{mm}) ; \mathcal{N}=$ number of individuals.

\begin{tabular}{|c|c|c|c|c|c|c|c|}
\hline \multirow[b]{2}{*}{ Group } & \multicolumn{5}{|c|}{ Dredge track } & \multicolumn{2}{|l|}{ Catches } \\
\hline & 1 & 2 & 3 & $\mathrm{~L}(\min -\max )$ & $\mathrm{N}$ & $\mathrm{L}(\min -\max )$ & $\mathrm{N}$ \\
\hline \multicolumn{8}{|l|}{ Bivalvia } \\
\hline Acanthocardia aculeata & & & & - & - & $55-85$ & 3 \\
\hline Acanthocardia tuberculata & & & & - & - & $35-68$ & 14 \\
\hline Chamelea gallina $\checkmark$ & 82 & & & $9-25$ & 82 & $25-37$ & 221 \\
\hline Donax trunculus $\checkmark$ & 31 & 4 & 1 & $13-31$ & 36 & $29-40$ & 5 \\
\hline Ensis siliqua & 1 & & & 71 & 1 & - & - \\
\hline Lutraria angustior & & & 1 & $*$ & 1 & $32-52$ & 9 \\
\hline Mactra corallina stultorum & & & 1 & 32 & 1 & $35-52$ & 6 \\
\hline Pharus legumen & 1 & & 2 & $55^{-*}$ & 3 & - & - \\
\hline Spisula solida $\checkmark$ & 57 & 2 & 1 & $9-25$ & 60 & $25-34$ & 173 \\
\hline Tellina tenuis & 45 & 3 & 12 & $10-18$ & 60 & - & - \\
\hline \multicolumn{8}{|l|}{ Echinoidea } \\
\hline Echinocardium cordatum & 1 & & 8 & $* *$ & 9 & $* *$ & 11 \\
\hline Total & 218 & 9 & 26 & - & 253 & - & 442 \\
\hline
\end{tabular}

$\checkmark$, Commercial clam species; *, both valves highly damaged; **, not measured.

corresponding to 31 and 38 individuals, respectively. No significant differences were observed in the proportion of damaged individuals in the beginning, middle and end of the dredge tracks $\left(\mathrm{K}-\mathrm{W}, \mathrm{H}=0.746\right.$, d.f. $=2, P_{\text {est }}=0.689$, $\left.P_{\text {exact }}=0.746\right)$.

Table 1 shows the species, mean number, damage score and length range of the individuals left in the path of the dredge, and species and length range of the individuals collected by the gear. As expected, species sensitive to dredging were the thin-shelled bivalves such as Tellina tenuis, Pharus legumen, Mactra corallina stultorum and Lutraria angustior, as well as the sea urchin Echinocardium cordatum, altogether showing a possible mortality of about $36 \%$. Thick-shelled bivalves such as Chamelea gallina, Spisula solida and Donax trunculus however, seem to be more resistant to the mechanical stress of dredging, showing a possible mortality of less than $5 \%$.

At the end of each tow, divers made immediate observations on the bottom area fished over by the gear. On most occasions, they found that only heavily damaged individuals remained on the seafloor, while undamaged or slightly damaged individuals had already burried themselves again. The only exceptions were two Pharus legumen and one Ensis siliqua, which appeared to be undamaged, suggesting that these organisms suffered internal damage.

\section{Aggregation}

Prior to fishing operations, divers estimated the background densities of two common scavenger species in the study area, the brittle star Ophiura albida and the hermit crab Pagurus spp. The densities were 0.62 and 0.30 individuals per $\mathrm{m}^{2}$, for the brittle star and for the hermit crab, respectively.

Figure 2A,B shows the evolution of the mean abundance of these two species, throughout the duration of the experiments. In the case of the brittle star (Figure 2A),

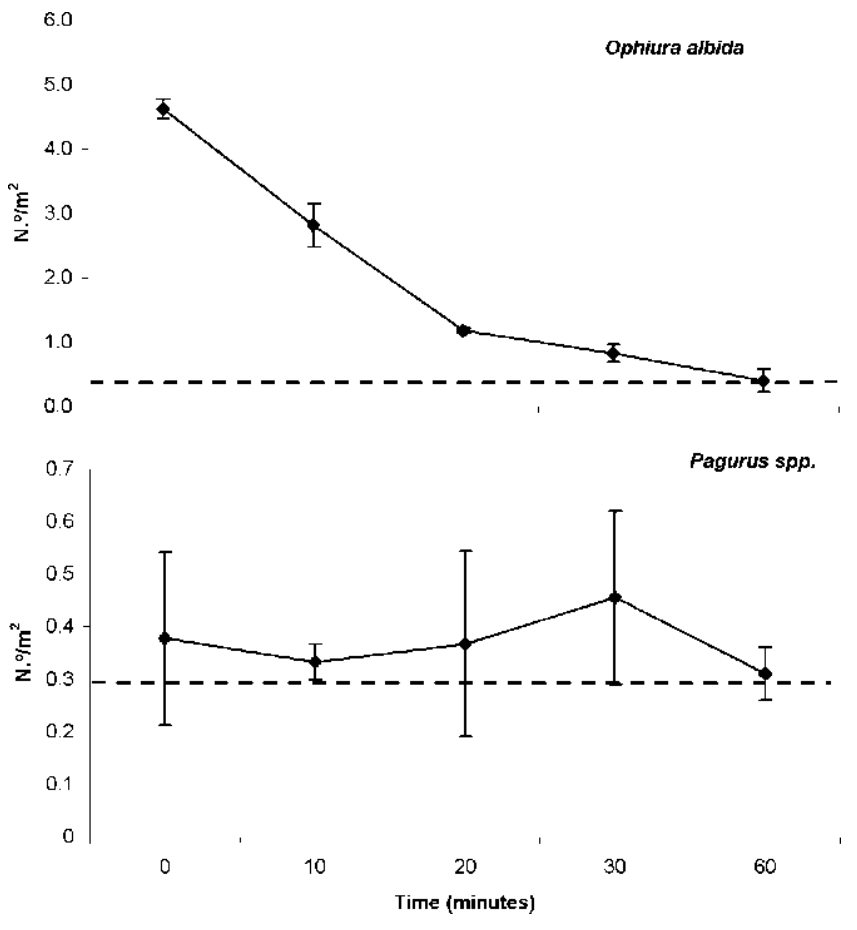

Figure 2. Mean density of Ophiura albida (top) and of Pagurus spp. (down) within the dredge track throughout the study period. Dashed lines indicate the mean background density and error bars indicate SD.

a rapid aggregation to approximately 8 times the background level was observed immediately after the tow. The mean abundance decreased to 2.85 individuals per $\mathrm{m}^{2}$ after 10 minutes, indicating that this species starts to disperse very quickly. The $\mathrm{K}-\mathrm{W}-\mathrm{ANOVA}$ on Rank analysis showed significant differences in the mean abundance of brittle stars before and after the tow $(\mathrm{K}-\mathrm{W}, \mathrm{H}=16.128$; d.f. $=5 ; P=0.006)$. The pair-wise multiple comparisons test 
Table 2. Results of the pair-wise multiple comparisons (Student-Newman-Keuls test) performed to test differences in the density of brittle star throughout the study period.

\begin{tabular}{ccccccl}
\hline Time $(\min )$ & 0 & 10 & 20 & 30 & 60 & Background \\
\hline 0 & - & $* *$ & $* *$ & $*$ & $*$ & $*$ \\
10 & & - & $* *$ & $* *$ & $* *$ & $* *$ \\
20 & & & - & $* *$ & $* *$ & $* *$ \\
30 & & & & - & $\mathrm{ns}$ & $\mathrm{ns}$ \\
60 & & & & - & $\mathrm{ns}$ \\
\hline
\end{tabular}

$*, p<0.01 ; * *, p<0.05 ;$ ns, not significant.

(Table 2) showed that no significant differences remained after 30 minutes.

Changes in mean abundance of hermit crabs in the dredge tracks is shown in Figure 2B. Although a slight increase in density after the tow was observed, the ANOVA analysis revealed no significant differences $(P=0.710)$ in abundance of hermit crabs before and after the tow.

\section{DISCUSSION}

\section{Track configuration and breakdown}

Although the dredge passage causes a large amount of sediment suspension in the water column, it was observed that sediment rapidly resettled independently of bottom type. In the present study, no data were obtained on the effect of dredging on the grain size composition of the bottom sediments. In the south coast of Portugal the bivalve fishery only occurs on very shallow waters (up to $15 \mathrm{~m}$ depth) on sandy bottoms that primarily consist of medium to coarse sediments. These areas are affected by tides, strong currents and wave action, therefore changes in the sediment granulometry due to dredging are not expected.

We found that the dredge path was deeper on sandy-mud sediments than in sandy sediments. It was also observed that the dredge track persisted for a longer period in finer sediments, varying from several days to few hours in tows performed in sandy-mud and sandy sediments, respectively. The disappearance of dredge tracks left on the bottom in both sediment types depended on tidal currents strength and wave action. Therefore where currents are weak, the dredge tracks may be recognisable for a long time and even a minor fishery may have a significant cumulative effect on bottom microtopography (Caddy, 1973).

\section{Mortality of the macrofauna left on the track}

Damage and mortality of benthic organisms that are not caught but that have come within the influence of the gear usually occurs during the passage of a dredge over the seafloor. Our results showed that mortality on the dredge path for the whole macrobenthic community was relatively low. Indirect fishing mortality on uncaught organisms has been found to be important in some dredge fisheries (e.g. Murawski \& Serchuk, 1989; Shepard \& Auster, 1991). Jenkins et al. (2001) assessed the impact of scallop dredging on benthic megafauna by direct observation of damage, both in the by-catch and in organisms left in the dredge tracks. Their results showed that major damage to large benthic invertebrates during scallop dredging occurs unobserved on the seabed, rather than in the by-catch. Similar findings were obtained by Fonds \& Groenewold (2000).

Gaspar et al. (in press) estimated and compared the total direct mortality of macrobenthos, caused by three types of clam dredges used in the Spisula solida fishery. They found significant differences in total direct mortality between different kinds of dredges, which were attributed to the mortality of animals in the dredge track as a direct result of physical damage inflicted by the dredge passage. These authors concluded that lower catching efficiencies led to a higher proportion of damaged individuals left on the dredge track, when compared with more efficient dredges. Such a relationship between catching efficiency and damage has also been observed by other authors (e.g. Caddy, 1973; Meyer et al., 1981). Therefore, the low mortality observed in our study can be explained by the high efficiency of capture of the dredge.

\section{Aggregation}

Post-fishing diving observations showed that brittle stars were attracted to the track region immediately after the tow to feed on material disturbed by the dredge. Following fishing, ophiuroids become very abundant in the track area at densities 8 times higher than the background density. However, after 10 minutes the mean abundance of brittle stars decreased sharply, indicating that this species dispersed rapidly. The low number of heavily damaged individuals left on the dredge tracks explains these results.

It is important to emphasise that in the present study almost all undamaged and slightly damaged individuals within the dredge track quickly reburied, indicating that the stress induced and/or damaged inflicted by dredging was not high enough to decrease the burrowing response after escaping through the bars of the retention grid. This suggests that predator induced mortality may not be significant for undamaged and slightly damaged individuals left temporarily exposed on dredge tracks. On the contrary, Maguire et al. (2002a) stated that uncaught scallops might suffer enhanced mortality due to dredge-induced stress in the same way as undersized discards. Several authors (Minchin et al., 2000; Jenkins \& Brand, 2001; Maguire et al., 2002b) observed that undersized scallop discards are more susceptible to predation due to a reduction in their response or inability to recess; indicating that indirect fishing induced mortality can be significant. Such mortality is, however, not relevant in the Portuguese clam fishery when the grid dredge is used, such as in this study and Gaspar et al. (2001), due to the selectivity of this gear. The comparison in size ranges between individuals from commercial species left in the track of the dredge and those caught by the gear (table 1), indicates that the dredge used in the study is highly selective, with most of the undersized organisms escaping between the bars of the metallic grid of the dredge during the tow.

We would like to thank the crew of RV Donax for their skilful handling of the boat and fishing gears. Sincere thanks are also due to three anonymous referees whose suggestions greatly improved the manuscript. This study was funded by the EC as part of the ECODREDGE project, contract number FAIR CT984465. 


\section{REFERENGES}

Caddy, J.F., 1973. Underwater observations on the tracks of dredges and trawls and some effects of dredging on a scallop ground. Fournal of the Fisheries Research Board of Canada, 30, $173-180$.

Fonds, M. \& Groenewold, S., 2000. Food subsidies generated by the beam trawl fishery in the Southern North Sea. In Effects of fishing on non-target species and habitats (ed. M.J. Kaiser and S.J. Groot), pp. 130-150. Blackwell.

Gaspar, M.B., Dias, M.D., Campos, A., Monteiro, C.C., Santos, M.N., Chícharo, A. \& Chícharo, L., 2001. The influence of dredge design on the catch of Callista chione (Linnaeus, 1758). Hydrobiologia, 465, 153-167.

Gaspar, M.B., Leitão, F., Santos, M.N., Chícharo, L., Dias, M.D. \& Monteiro, C.C. A comparison of direct macrofaunal mortality using three types of Portuguese clam dredges. ICES Journal of Marine Science (in press).

Jenkins, S.R., Beukers-Stewart, B.D. \& Brand, A.R., 2001. Impact of scallop dredging on benthic megafauna: A comparison of damage levels in captured and non-captured organisms. Marine Ecology Progress Series, 215, 297-301.

Jenkins, S.R. \& Brand, A.R., 2001. The effect of dredge capture on the escape response of the great scallop, Pecten maximus (L.): implications for the survival of undersized discards. Fournal of Experimental Marine Biology and Ecology, 266, 33-50.
Kaiser, M.J. \& Spencer, B.E., 1994. Fish scavenging behaviour in recently trawled areas. Marine Ecology Progress Series, 126, 31-38.

Maguire, J.A., Coleman, A., Jenkins, S. \& Burnell, G.M., 2002 b. Effects of dredging on undersized scallops. Fisheries Research, 56, 155-165.

Maguire, J.A., O’Donoghue, M., Jenkins, S. Brand, A. \& Burnell, G.M., 2002a. Temporal and spatial variability in dredging induced stress in the great scallop Pecten maximus (L.). Journal of Shellfish Research, 21, 81-86.

Meyer, T.L., Cooper, R.A. \& Pecci, K.J., 1981. The performance and environmental effects of a hydraulic clam dredge. Marine Fisheries Review, 43, 14-22.

Minchin, D., Skjaeggestad, H., Haugum, A.G. \& Strand, O., 2000. Righting and recessing ability of wild and native cultivated scallops. Aquaculture Research, 31, 473-474.

Murawski, S.A. \& Serchuk, F.M., 1989. Environmental effects of offshore dredge fisheries for bivalves. ICES CM 1989/K:27, $12 \mathrm{p}$.

Shepard, A.N. \& Auster, P.J., 1991. Incidental (non-capture) damage to scallops caused by dragging on rock and sand substrates. In An International Compendium of Scallop Biology and Culture (Ed. S.E. Shumway and P.A. Sandifer), pp. 219-230. Baton Rouge, Louisiana: World Aquaculture Society. 